\title{
DESIRE:Disseminating Educational Science, Innovation and Research in Europe
}

\section{A European project investigates on how science information can be communicated and disseminated to teachers in an effective way}

\author{
Silvia Panzavolta \\ Department of Communication, Documentation and New Media Languages \\ Istituto Nazionale di Documentazione per l’Innovazione e la Ricerca Educativa (INDIRE) \\ Florence, Italy \\ s.panzavolta@indire.it
}

\begin{abstract}
The paper illustrates the research activities carried out by the European DESIRE project dealing with dissemination strategies of European projects outcomes and results and takes into account specific stakeholders in the projects life cycle. Preliminary findings are given and commented and some recommendations are drawn based on data collected so far.
\end{abstract}

Keywords-dissemination activities; communication strategies; science information; science projects; knowledge sharing; European dimension;

\section{INTRODUCTION}

The DESIRE project (Disseminating Educational Science, Innovation and Research in Europe) [1] develops models of diffusion and exploitation to ease the spreading of science education projects results to teachers. The project started in December 2011 and will end in November 2013. The DESIRE project is carried out by European Schoolnet (EUN) [2] together with, INDIRE [3], CRECIM - Universitat Autonoma de Barcelona (UAB) [4], Dansk Naturvidenskabsformidling [5] and Ecsite, the European Network of Science Centres and Museums [6], and is funded under the European Commission's Lifelong Learning Programme (DG Education and Culture).

The primary objective is to identify how new project results on methods and practices in science education can reach teachers and schools more efficiently.

The main data collection activities so far have been questionnaires and Online Discussion Events (ODE), both of them targeting at different stakeholders in the science communication lifecycle, namely: science teachers, science project planners, policy-makers and organizers of science events, activities and expositions in museums.

\section{PROJECT FUNDAMENTALS}

\section{A. Background research}

Many dissemination methods have been identified by previous European projects in order to communicate best practices in science education, such as awareness raising campaigns, panels of pedagogical experts, online teacher training material, learning resource exchange portals, mainly having an Open Education Resource (OER) approach, as defined by UNESCO [7].

Each model has strengths but several obstacles can be highlighted. One of the major problems is, on the one hand, the "cognitive" or "information overload" teachers are exposed since there are large amounts of information available in the Web; on the other hand, teachers often feel that selecting among those resources is actually not part of their ordinary job but more a kind of voluntary activity. In a technical note by the European Commission (2010) dealing with European teachers' vision, it is clearly stated that one of major digital competences teachers and students have to develop as part of the Europe 2020 strategy is "judging the relevance and trustworthiness of sources and avoiding knowledge overload” [8].

Another problem is that in many countries, school communication is rather hierarchical: head teachers are informed about science projects but do not always share the information they come across to all the school teachers, a problem identified by the knowledge sharing in education strand of research and dealt with by OECD in a recent Toolkit (2009) for improving school leadership [9].

Finally, another obstacle that can be identified is that many science teaching material is on the use of ICT whilst teachers, especially new teachers, search for pedagogy advice and teaching methodology material, being ICT infrastructure not always available in their classrooms. A report by the Commission, addressed to policy makers (2010), underlines that the primary teachers' requirement is, apart from formal inservice training programs, the possibility of "accessing knowledge through exchange between new and experienced teachers" and of counting on expert professionals such as mentors or expert peers and on collaborative learning environments [10].

Recently, the European Commission (2012) published a paper on which part of the analysis framework definition was based. The text [11], titled "Communicating EU Research and Innovation: a Guide for project participants” was considered as 
a very relevant reference material by the project Consortium who will feed the recommendations by the Commission into the DESIRE project final deliverable.

\section{B. Projects connected}

The DESIRE project is building its knowledge and evidence taking into account many European projects on science education, such as SCIENTIX [12], XPLORA [13], inGenius [14], just to mention some and, in a more general sense, the dissemination and communication strategies put in place to reach the intended targets by EUN, running dozens of projects at an international level, and by its network of 30 Ministries of Education (MoE) running projects at national and regional level. All these previous practices were taken into account as a basis for further research and discussion with relevant stakeholders.

\section{THE PROJECT MILESTONES}

The first part of the project was dedicated to research activities, data collection and analysis concerning different dissemination strategies used within European projects, especially Life Long Learning (LLP) Projects; to analyze the impact among science teachers of these methods; to analyze the uptake of project results by policy makers; to propose changes, improvements and new methods to disseminate results and discuss with relevant stakeholders.

In order to gather qualitative and quantitative feedback to propose new dissemination strategies, the project Consortium identified two main methods: questionnaires targeted at the four main stakeholder groups involved in the dissemination lifecycle and discussion events with those target groups (namely science teachers, science project planners, policymakers and organizers of science events and of activities and expositions in museums).

\section{A. Analysis framework definition}

Generally speaking, “dissemination” means spreading something widely, promulgating extensively, broadcasting or dispersing. In a more narrow definition, it can de defined as the "process of sharing information and knowledge, ensuring the physical availability of materials to the target audience and making results comprehensible to those who receive them". It was also discussed whether dissemination basically consisted of sending information to an audience, without necessary direct contact with the receiver, and without a direct response method and whether "dissemination" was considered the same as "divulgation" or "popularization". The Consortium came to and operational definition within the DESIRE project as follows, based on Harmsworth et al. definition (2000) [12]: "We will refer to dissemination as the process by which, using certain strategies, results of a project are made available, comprehensible and usable to be adopted by potential users". In particular, the Consortium found it useful the definition in relation to the objectives that dissemination can have, or "dissemination for awareness", "dissemination for understanding” and "dissemination for action”, since it offers a systemic view of dissemination strategies purposes.

\section{B. Dissemination barriers and facilitars}

Some dissemination obstacles were identified based on previous EU project experiences and literature, mainly: Institutions' low priority to wider dissemination; project coordinators and other participants' practical difficulties (e.g. time constraints); gap between research and policy (driven by different incentives, different timeframes for action, different standards for evidence, style and media typically used by researchers); technical and infrastructural barriers for the users of information accessing information; barriers regarding the format, length, style or approach, content and language in which results are presented; other structural constraints that avoid information reaching the target audience and being understood by them (e.g. time and resource limits, evaluation requests, extension of national programs).

As for the facilitators, the project identified the following ones: incorporating the types and levels of knowledge needed into the forms and language preferred by the user; combining dissemination methods; including information that users have identified as important, and information that users may not know to request but that they are likely to need; taking advantage of existing resources, relationships, and networks to the maximum extent possible while building new resources as needed by users; implementing effective quality control mechanisms to assure that information to be included is accurate, relevant, and representative; establishing linkages to resources that may be needed to implement the information usually referred to as technical assistance.

The following table I was used as a schema to discuss with relevant stakeholders and to design questionnaire items and discussion statements.

TABLE I. DISSEMINATION STRATEGIES SCHEMA

\begin{tabular}{|l|l|l|}
\hline \multicolumn{2}{|c|}{ Dissemination strategies and their advantages/disadvantages } \\
\hline $\begin{array}{l}\text { Sharing project working } \\
\text { documents }\end{array}$ & $\begin{array}{l}\text { Advantages } \\
\text { Research } \\
\text { findings to } \\
\text { particular } \\
\text { groups }\end{array}$ & $\begin{array}{l}\text { Disadvantages } \\
\text { audience }\end{array}$ \\
\hline Sharing research reports & $\begin{array}{l}\text { Single reference } \\
\text { point }\end{array}$ & $\begin{array}{l}\text { Limited } \\
\text { audience }\end{array}$ \\
\hline $\begin{array}{l}\text { Publishing in academic } \\
\text { journals }\end{array}$ & $\begin{array}{l}\text { Reaching } \\
\text { scientific } \\
\text { community }\end{array}$ & $\begin{array}{l}\text { Limited } \\
\text { audience }\end{array}$ \\
\hline $\begin{array}{l}\text { Publishing in professional } \\
\text { journals }\end{array}$ & $\begin{array}{l}\text { Practitioner- } \\
\text { oriented } \\
\text { audience }\end{array}$ & $\begin{array}{l}\text { Lack of } \\
\text { scientific rigor }\end{array}$ \\
\hline Using mass media channels & $\begin{array}{l}\text { Wide audience } \\
\text { reached }\end{array}$ & $\begin{array}{l}\text { Superficial } \\
\text { message }\end{array}$ \\
\hline Using Internet / emails & $\begin{array}{l}\text { Immediacy } \\
\text { Networking } \\
\text { Low expenses }\end{array}$ & $\begin{array}{l}\text { Uncontrolled } \\
\text { potential } \\
\text { Risk of } \\
\text { overload }\end{array}$ \\
\hline $\begin{array}{l}\text { Printing breif documents } \\
\text { with core ideas }\end{array}$ & $\begin{array}{l}\text { Declare core } \\
\text { issues }\end{array}$ & $\begin{array}{l}\text { Limited } \\
\text { audience }\end{array}$ \\
\hline Producing training material & $\begin{array}{l}\text { Applied } \\
\text { knowledge }\end{array}$ & $\begin{array}{l}\text { Expenses } \\
\text { Limited } \\
\text { audience }\end{array}$ \\
\hline
\end{tabular}




\begin{tabular}{|l|l|l|}
\hline \multicolumn{3}{|c|}{ Dissemination strategies and their advantages/disadvantages } \\
\hline \multicolumn{1}{|c|}{ Strategies } & \multicolumn{1}{|c|}{ Advantages } & \multicolumn{1}{|c|}{ Disadvantages } \\
\hline $\begin{array}{l}\text { Using social } \\
\text { networks/media }\end{array}$ & $\begin{array}{l}\text { Networking } \\
\text { Interaction } \\
\text { Exploitation }\end{array}$ & $\begin{array}{l}\text { Time- } \\
\text { consuming } \\
\text { Low active } \\
\text { engagement }\end{array}$ \\
\hline Selecting intermediaries & $\begin{array}{l}\text { Locally } \\
\text { supported }\end{array}$ & $\begin{array}{l}\text { Needs for } \\
\text { engagement and } \\
\text { agreement } \\
\text { Time- } \\
\text { consuming }\end{array}$ \\
\hline $\begin{array}{l}\text { Using participatory } \\
\text { techniques }\end{array}$ & $\begin{array}{l}\text { Time- } \\
\text { consuming } \\
\text { Limited } \\
\text { audience }\end{array}$ \\
\hline
\end{tabular}

Based on the above framework definition, the project partners proceeded in gathering qualitative and quantitative data.

\section{DATA COLLECTION METHODS}

As presented above, both qualitative and quantitative tools were used by all partners in their countries.

\section{A. Questionnaires to relevant stakeholders}

Questionnaires items were prepared by CRECIM (UAB). Each partner contacted a number of stakeholders, according to stakeholder group, presented the research objectives and invited them to fill in the corresponding questionnaire. Questionnaires were meant to gather quantitative data even though some open-ended questions were provided to capture some qualitative feedback as well. Questionnaires were translated into several Member States languages, namely French, German, Portuguese, Danish, Greek, Spanish, Italian, Romanian and Polish. A pilot testing of the questionnaire was also done before administration. Online questionnaires were then administered online by using the Survey Monkey tool.

\section{B. Discussion events}

Discussion events were the main qualitative data collection tools identified. Discussion events were held in different formats, according to technological tools available and to audience specificities. There have been three main formats:

1) Online platform for discussion: the project set up a platform (mainly a forum with some instant messaging capabilities) to run online three-day workshops on a specific theme connected with dissemination strategies. Each partner used this modality at least once. So far, two such events were organized for teachers, one for policy makers, two for projet managers, two for science museums organizers and one for science events organizers.

2) One-hour session seminar: as an alternative to the previous mode described, partners organized shorter seminars having a more focussed approach where the moderator of the discussion would have asked, in turn, to all participants to express their views on a series of issues relevant for the project. The tools used where Google hangouts, Skype conference calls, LinkedIn Groups, and Adobe Connect platform facilities. So far, one such event was organized for science events organizers and one for science museums organizers.

3) Face-to-face meetings: meeetings and seminars were also organized, often in connection with other projects dealing with science education or having a relevant target group involved. Within these meetings, a one-and-half session was organized to gather participants' feedback and to get useful ideas for successful dissemination strategies. So far, one such event was organized for teachers and one for policy makers.

Through discussion events, the project has so far contacted over one hundred science teachers, twenty science events and museum organizers, twenty policy makers and eighteen project managers.

\section{ANALYSIS OF RESEARCH RESULTS}

Different questionnaires about dissemination were designed and administered to relevant stakeholders involved at different levels in projects funded by the EC (7th Framework Programme), by the EACEA (Lifelong Learning Programme) or by other institutions, such as ministries of education of different countries, public or private organisms or societies. In particular, 45 science education projects were selected and various professionals dealing with the project were contacted to invite them to complete the questionnaire.

Table II shows the list of projects in which the contacted professionals were involved.

TABLE III. PROJECTS AND THEIR CONTEXTS

\begin{tabular}{|c|c|c|}
\hline \multicolumn{3}{|c|}{ Projects contacted } \\
\hline $\begin{array}{c}\text { Projects funded } \\
\text { by the EC (7th FP) }\end{array}$ & $\begin{array}{c}\text { Projects funded } \\
\text { by the EACEA (LLP) }\end{array}$ & $\begin{array}{c}\text { Projects funded } \\
\text { by public } \\
\text { (national) } \\
\text { organisms }\end{array}$ \\
\hline $\begin{array}{c}\text { CoReflect } \\
\text { Engineer } \\
\text { Establish } \\
\text { Fibonacci } \\
\text { Ingenious - ECB } \\
\text { Inquire } \\
\text { Iris } \\
\text { Nanoyou } \\
\text { Nanochannels } \\
\text { OSR } \\
\text { Pathway } \\
\text { Primas } \\
\text { Sails } \\
\text { Scientix } \\
\text { Sed } \\
\text { S-Team } \\
\text { Traces } \\
\text { Twist } \\
\text { U4Energy } \\
\text { Xplore Health }\end{array}$ & $\begin{array}{c}\text { AESTIT } \\
\text { Compass } \\
\text { CrossNet } \\
\text { eTwinning } \\
\text { EU Train } \\
\text { EU-HOU } \\
\text { FEAST } \\
\text { GIMMS } \\
\text { ICT for IST } \\
\text { Inspire } \\
\text { Items } \\
\text { SceTGo } \\
\text { SETAC } \\
\text { Spice } \\
\text { Stencil } \\
\text { UniSchoolsLab }\end{array}$ & $\begin{array}{c}\text { Compec (Spain) } \\
\text { Epse (UK) } \\
\text { EUSEA (AT) } \\
\text { MUSE (ES) } \\
\text { PON Scienze } \\
\text { (IT) } \\
\text { Projekt X (DA) } \\
\text { ROSE project } \\
\text { (NO) } \\
\text { Scienze } \\
\text { Integrate (IT) } \\
\text { SINUS (DE) } \\
\text { STELLA (IT) } \\
\text { STENCIL (IT) }\end{array}$ \\
\hline
\end{tabular}

\section{A. Questionnaires analysis}

Questionnaires are referenced below as Q1 (to project managers), Q2 (to teachers) and Q3 (to policy makers). There have been 21 responses to Q1, 106 responses to Q2 (51 in English and 55 in other languages) and 8 responses to Q3. 
The main points coming out from Q1 can be summed-up as follows.

Eighty-five per cent of science education projects produce and disseminate teaching and learning materials, tools or environments. Other types of outcomes that are usually developed by science education projects are guidelines of good practices, networks of people and materials for teacher training. These types of outcomes were developed and intended to be disseminated by more than $60 \%$ of the projects listed in Table 2. On the other hand, projects' outcomes that are not so frequently disseminated correspond to theoretical or empirical research findings.

All science education projects are intended to reach teachers and professors. This is the common target audience that all science education projects share. About $75 \%$ of funded science education projects also intend to reach other target audiences such as teacher trainers, policy-makers and other project managers. Less than a third of the analysed projects intend to reach science events' organisers, science centres' managers, editorials or other society agents like parents or industries.

All three types of dissemination strategies (text-based, media-based and face-to-face) are frequently used in funded projects. However, not all specific dissemination strategies are used with the same frequency.

According to the reported results, public project documents or reports seem to be the most common text-based strategy to reach target audiences. Articles in academic journals and/or professional journals are not so widely used to disseminate project outcomes.

Concerning media-based strategies, Internet (e.g. portals, websites) is by far the most common dissemination channel to reach target audiences. In particular, projects' websites and the ones created by the ministries of education are the most common examples of Internet portals through which project outcomes are disseminated. Other dissemination channels such as mass media or social networks do not appear to be used in the analysed projects. One possible reason for the little use of these more recent channels can be found in the first Desire online discussion event, where social networks such as Facebook or Twitter were considered little appropriate to disseminate projects' outcomes to teachers due to the low traffic that these social networks seem to bring to project websites. Regarding mass media such as TV documentaries as dissemination channels, they are considered strategies that tend to have a very poor effect on disseminating project results or ideas in depth.

Two main categories were distinguished within face-to-face dissemination strategies: traditional events such as conferences or seminars, and participatory techniques such as face-to-face communities of practice or workshops. These two dissemination strategies are used in funded projects with approximately the same high frequency.

Project outcomes such as teaching and learning materials or teacher training materials are mainly disseminated combining reports, brief documents, websites or participatory techniques. Outcomes like empirical research findings, theoretical contributions or reviews are mainly disseminated using academic or professional journals, websites and face-to-face traditional events such as conferences.

As for the Q2 feedback, the main trends are described below.

Teaching and learning materials, tools or environments are the most common science education projects' outcomes that reach teachers since $86 \%$ of them recognize that this is the kind of outcome of which they have been informed from funded projects. Other types of outcomes that usually reach teachers are guidelines of good practices, and networks of people. These types of outcomes reached about $50 \%$ of the teachers who answered Q2. The types of outcomes that have lower impact among teachers (less than one third of teachers) are: reviews of already existing literature or studies, theoretical contributions and findings from empirical research studies.

Teachers usually get to know projects' outcomes by means of all three types of dissemination strategies (text-based, media-based and face-to-face) used in funded projects. However, not all specific dissemination strategies reach teachers with the same frequency. According to the reported results, public project documents or reports seem to be the most common text-based strategy by means of which projects' outcomes reach teachers. Articles in academic and/or professional journals are not so widely used by teachers to reach project outcomes.

Concerning media-based strategies, Internet (e.g. portals, websites) is by far the most common dissemination channel to reach teachers. In particular, projects' websites are the most common examples of Internet portals through which teachers get to know projects' outcomes. Other dissemination channels such as newsletters, mass media or social networks do not appear to be so frequently used by teachers to get informed of funded projects. During the first Desire on-line discussion event for teachers, some teachers who were enthusiastic about the use of social networks such as Facebook or Twitter expressed that the fact that they can choose the kind of information they want to receive is a useful feature of a dissemination channel.

Finally, two main categories were distinguished within face-to-face strategies: traditional events such as conferences or seminars, and participatory techniques such as face-to-face communities of practice or workshops. These two dissemination strategies are used by teachers with approximately the same high frequency. Although, in general terms, all three types of strategies seem to be used very frequently, specific strategies are used more than others by teachers to reach certain types of project outcomes.

Concerning the Q3 results, the main points are given below.

Teaching and learning materials, tools or environments, networks of people and repositories of resources and practices are the most common science education projects' outcomes that reach policy-makers since more than $60 \%$ of them recognize that this is the kind of outcome of which they have been informed from funded projects. The types of outcomes which have lower impact among policy-makers are: reviews of already existing literature or studies, theoretical contributions, 
findings from empirical research studies and materials for teacher training.

Policy-makers usually get to know projects' outcomes by means of all three types of dissemination strategies (text-based, media-based and face-to-face) used in funded projects. However, not all specific dissemination strategies reach policymakers with the same frequency. According to the reported results, public project documents or reports and brief documents seem to be the most common text-based strategy by means of which projects' outcomes reach policy-makers. Articles in academic and/or professional journals are not used by policy-makers at all to reach project outcomes.

Concerning media-based strategies, Internet (e.g. portals, websites) is the most common dissemination channel to reach policy-makers. Other dissemination channels such as mass media or social networks do not appear to be used by policymakers to get informed of funded projects.

Finally, traditional events such as conferences or seminars seem to be the most effective face-to-face dissemination strategy used by policy-makers.

\section{B. Discussion events discourse analysis}

Discussion events were recorded and, according to their format, researchers accessed either the audio-video version or the written one. Starting from those transcripts, researchers clustered comments and suggestions according to crucial topics (i.e. type of strategies used, dissemination strategy audience, perceived quality of dissemination activities, evaluation tools re dissemination campaigns, communication barriers etc.) as investigated through the questionnaires items. The main outcomes of discussion events concerning science events and science museums organizers can be summed-up as follows.

As to dissemination channels, most science museum and events organizers recognize that they rely on direct contact with scientists to get information, as well as for understanding how a topic is tackled. The live human network seems more appreciated than the internet social network. Conferences on science communication and education are seen as a very good access to new projects and practice.

Concerning research findings on informal science education, many science museum organisers agree that there is a need for more research on informal science education or for a common European database were all on-going and finished science education projects would have to deliver their results. This searchable database would include material for specific groups of interest, and results from research-actions experiences which do not usually get published in academic journals.

As for the involvement of stakeholders, science museum organizers also agree on the need for involving the potential users in meetings or in an advisory board from the beginning of a funded project for dissemination purposes.

About national support and initiatives, science museum organizers recognize the potential of national databases, teacher and science educator networks, and experts consulting, in order to connect people and to redirect them to appropriate sources and references.
As to reference database/portals, many science museum organisers consider that there is not one specific place on the Internet to start their research about projects' outcomes or products. One strong suggestion is the idea of building one single EU database, organised in such a way to enable teachers, communicators, trainers to find through keywords and tags straight links to projects, reports and published references resulting from all EU projects related to a certain topic. Specifically, such a unique database would be a perfect starting point for practitioners seeking resources which come from different projects focused on similar topics.

\section{PRELIMINARY CONCLUSIONS}

Our results show that a significant number of project managers (two thirds of respondents) consider that they do not receive too much information from science education projects. Similarly, about half of the teachers and policy-makers who answered the questionnaires also appraised the amount of information received as scarce or non-existent. Given this situation, it seems necessary to look for improved ways to carry out the dissemination of projects' outcomes in order to overcome the gap between different stakeholders.

Comparing projects' managers intentions with regards to dissemination and the impact of specific actions perceived by different stakeholders, some needs have been identified that should be taken into account in order to improve how dissemination is carried out. This study evidences that all science education projects are intended to reach teachers, and most of these projects also intend to reach other target audiences such as teacher trainers, policy-makers and other project managers. According to the results of this study, teachers and teacher trainers, as the main target audience, are usually contacted through multiple text-based strategies, websites and face-to-face strategies in order to make project outcomes known and understood by these audiences. In fact, they are the only target audiences that are involved in face-toface participatory techniques, such as workshops and communities of practice, whereas other target audiences like policy-makers and other projects managers, are usually reached by a fewer number of dissemination strategies such as public reports, articles, websites and traditional events (e.g. conferences).

As evidenced in the on-line discussion events, some project managers have some reservations about using participatory techniques as dissemination strategies since they are considered very demanding and time-consuming, they require a lot of involvement of all parts, and they do not tend to have impact at a large scale. There seems to be also some pressure for scaling up innovations so that research-based practices are more widely spread among teachers. Given this appraisal, we can interpret that project managers decide to invest time and effort to use participatory techniques in case they intend to reach and have a deep impact on the main target audiences and potential users: teachers and teacher trainers. 
While teachers seem to be keener to use dissemination strategies that support them in their teaching practice and that allow them to interact and network with other teachers and researchers (e.g. face-to-face strategies, social media, etc), other target audiences such as policy-makers and science museum organizers stress the need for more media-based dissemination strategies such as online portals that were considered by practitioners a reference contact point that may facilitate the search for projects' outcomes. All of them agree on the need for involving target audiences throughout the lifetime of projects as intermediate stakeholders in order to have a higher impact in practice, playing and active role in the dissemination plans and actions.

Concerning the characteristics of the dissemination strategies, our results evidence that teachers and policy-makers recognize that main dissemination strategies through which they reach projects' outcomes (i.e. project reports, websites and traditional events) usually use English as a preferential language and take a considerable amount of time. This is a contrast to what some teachers and policy-makers state when commenting on the gap between research and practice or research and educational policy. Moreover, policy-makers recognize that they often do not have the time to pay attention to project results published in the style and media typically used by researchers. Some teachers also emphasize the need for including dissemination materials in other languages than English and the need for organizing more dissemination initiatives (e.g. conferences) at a local or regional level.

Regarding the quality of dissemination actions, we have also identified some needs that deserve our attention. Although most project managers who participated in our study recognized to feel satisfied about the dissemination plan and actions they had carried out, it is also the case that many of them claim that it is difficult to appraise the quality of dissemination actions since there is a lack of criteria to evaluate it. The most common criterion of evaluation is the number of people who are reached using any of the dissemination strategies implemented in the project. This quantitative indicator seems necessary to evaluate whether dissemination actions make project outcomes available to the target audiences. However, this criterion does not seem to evaluate dissemination actions sufficiently in depth considering that dissemination also involves making project outcomes understandable and usable in order to facilitate their use or exploitation. Other qualitative indicator used in projects refers to the target audiences' perception of the quality of the project. This criterion might allow evaluating whether target audiences consider that dissemination channels are usable and the outcomes are clear, useful and ready to be used in practice. However, this criterion seems difficult to use in order to measure the quality of a dissemination plan since it would require surveys or interviews to participants. Therefore, there seems to be a need for developing these kinds of instruments that allow appraising the quality of dissemination actions. As it has been also evidenced in this study, one of the indicators of quality that should be considered has to do with the incentives or rewarding system (e.g. equipment for the school, training, human mediation and support) provided to teachers.

In sum, these preliminary results of the DESIRE project point out some actions that might be carried out in order to improve how dissemination is usually planned and carried out. In this sense, the following phase of the Desire project will consist of elaborating guidelines that might contribute to improve the current situation regarding dissemination of science education projects' outcomes.

\section{DISSEMINATION STRATEGIES RECOMMENDATIONS AND TOOLKIT}

From this extensive international research activities and data analysis, at present some recommendations can be derived:

- Further adjustments to the deadlines of deliverables within the lifetime of a project are necessary to ensure the produced materials are available on time.

- More flexible time structures for the lifetime of the projects (e.g. longer projects) would facilitate the dissemination actions.

- Projects devoted to produce outcomes might be followed by funded projects specifically addressed to disseminate and exploit those results.

- Teachers' networks should be supported and potentiated after funded projects finish so that scaling up is possible afterwards.

- It is essential to establish strong contact and cooperation with teacher training institutions and policy-makers during the lifetime of the project and to develop local consulting commissions involving teachers, researchers, students' families, school principals and administrators, and other relevant actors.

- It is advisable to involve stakeholders as intermediate agents, ambassadors or members of the steering committee from the beginning of a funded project to spread the word of the project at a regional/national level, contributing to reach the target audience and to create a wider network.

- More mass media (e.g. newspapers) should be used for dissemination purposes of funded projects in order to have a larger impact among teachers.

- Any type of incentive (remuneration, recognition, network, training, equipment for school, etc) should be provided to teachers or other stakeholders involved in the project.

- The usability and usefulness of some dissemination channels (e.g. project websites) should be improved and other channels (e.g. social networks, mass media) are suggested to be included so that people do not get lost. 
- It is necessary to include dissemination materials in other languages than English and to organize more dissemination initiatives (e.g. conferences) at a local or regional level.

- It is important to provide guidelines and support to stakeholders so that they can use or apply what has been disseminated and facilitate a drift from the practiced teaching modes to new, more satisfying ones.

- A systemic view of the dissemination actions should be guaranteed, taking into account the curriculum, school organization, teachers' current practices, affective and emotional relationship with students, teachers' social recognition, incentives, government implication, teachers centres' involvement, etc.

- Projects should document experiences and present them in a flexible way (e.g. case studies, scripts for teachers, movies of educational activities) in order to spread good practice and generate adaptive processes so that stakeholders can learn from past experiences.

- Projects' outcomes should include specific directions on how to improve teachers' Pedagogical Content Knowledge about the specific theme of the proposal.

- Brief messages may facilitate the communication between researchers and policy-makers, recognizing that policy-makers have an important role in the process of establishing effective teacher training courses.

- More media-based dissemination strategies should be used instead of so many text-based strategies. There is a need for a common European and local databases were all on-going and finished science education projects would have to deliver their results.

The expected outcome of the project is to deliver a toolkit, that will be ready by November 2013 and made publicly available. The toolkit will contain a set of guidelines, addressing the various stakeholder groups, on how best disseminate project outcomes to intended target audience and will describe the main results from the DESIRE research activities. Several international workshops will also be held by partners by the end of the project (November 2013) in order to present a draft version of the toolkit and gather further feedback for finalizing it. The next exploitation workshops will be held in May (science events organizers, Israel), June (science museums organizers, Sweden), and August (teachers, Belgium).

\section{ACKNOWLEDGMENT}

Author thanks the work done by the Consortium partners, and in particular María Isabel Hernández Rodríguez (CRECIM, $\mathrm{UAB}$ ) and Roser Pinto (CRECIM, UAB) for their research support and expertise, Maité Debry (EUN) and Xenia Lauritsen (EUN) for their excellent coordination work, Didier Laval (Ecsite), Marzia Mazzonetto (Ecsite), Estrid Brandorff (DFN), Mikkel Bohm (DFN), Karin Mortensen (DNF), Agueda Gras (EUN), and Maria Guida (INDIRE) for their relevant contribution to the project outcomes.

\section{REFERENCES}

[1] The DESIRE project website is accessible at: http://desire.eun.org/.

[2] European Schoolnet website, accessible at: http:// http://www.eun.org/.

[3] INDIRE is the Italian National Institute for Educational Innovation, Research and Documentation. It is a public research insitute, connected with the Italian Ministry of Education and supporting it in the management of several national projects. The institute is however autonomous as for its research activities. The INDIRE website is accessible at: http:// http://www.indire.it/.

[4] The CRECIM (UAB) website is accessible at: http://www.crecim.cat/portal/.

[5] The Dansk Naturvidenskabsformidling website is accessible at: http://www.formidling.dk/.

[6] The Ecsite website is accessible at: http://www.ecsite.eu/.

[7] Commonwealth of Learning, "Guidelines for Open Educational Resources (OER) in Higher Education”, Unesco, 2011, accessible at: http://www.unesco.org/new/en/communication-and-information/accessto-knowledge/open-educational-resources/

[8] European Commission, Directorate-General for Research and Innovation, "Communicating EU Reasearch and Innovation: a Guide for Project Participants, Luxembourg: European Union, 2012, accessible at: http://ec.europa.eu/research/social-sciences/pdf/communicatingresearch_en.pdf.

[9] Organisation for Economic Co-operation and Development, "Improving School Leaderhip: the Toolkit”, 2009, available at: http://www.oecd.org/edu/school/44339174.pdf.

[10] European Commission, Joint Research Centre Institute for Prospective Technological Studies, “The Future of Learning: European Teachers' Visions”, Luxembourg: European Communities, 2010.

[11] European Commission, Directorate General for Educaation and Culture, "Developing Coherent and System-wide Induction Programmes for Beginning Teachers: a Handbook for Policy Makers”, Brussels, 2010.

[12] The SCIENTIX project website is accessible at: http://www.scientix.eu/.

[10] The XPLORA project website is accessible at: http://www.xplora.org/.

[11] The inGenius project website is accessible at: http://www.ingeniousscience.eu/web/guest/about/.

[12] Harmsworth S., Turpin S., "Creating an Effective Dissemination Strategy: An Expanded Interactive Workbook for Educational Development Prnjects”, Higher Education Funding Council for England (HEFCE), 2000

\section{Creative Commons Attribution License 4.0 (Attribution 4.0 International, CC BY 4.0)}

This article is published under the terms of the Creative Commons Attribution License 4.0

https://creativecommons.org/licenses/by/4.0/deed.en_US 